\title{
Legislações e recomendações brasileiras relacionadas à saúde e segurança ocupacional dos trabalhadores da saúde
}

\author{
Zilah Cândida Pereira das Neves ${ }^{1}$, Anaclara Ferreira Veiga Tipple ${ }^{2}$, Katiane Martins Mendonça ${ }^{3}$, \\ Adenícia Custódia Silva e Souza ${ }^{4}$, Milca Severino Pereira ${ }^{5}$
}

\footnotetext{
${ }^{1}$ Enfermeira, Doutora em Enfermagem. Professor Horista Assistente da Pontifícia Universidade Católica de Goiás. Goiânia, GO, Brasil. E-mail: zilahcpneves@gmail.com.

${ }^{2}$ Enfermeira, Doutora em Enfermagem. Professor Adjunto da Universidade Federal de Goiás. Goiânia, GO, Brasil. E-mail: anaclara.fen@gmail.com.

${ }^{3}$ Enfermeira, Doutora em Enfermagem. Professor de Magistério Superior Classe A do Instituto Federal de Educação, Ciência e Tecnologia de Goiás. Goiânia, GO, Brasil. Email: katiane2303@gmail.com.

${ }^{4}$ Enfermeira, Doutora em Enfermagem. Professor Adjunto da Pontifícia Universidade Católica de Goiás. Goiânia, GO, Brasil. E-mail: adeniciafen@gmail.com.

${ }^{5}$ Enfermeira, Doutora em Enfermagem. Professor Adjunto da Pontifícia Universidade Católica de Goiás. Goiânia, GO, Brasil. E-mail:

milcaseverino@gmail.com.
}

Recebido: 24/03/2016

Aceito: 20/09/2016.

Publicado: 17/04/2017.

Como citar esse artigo: Neves ZCP, Tipple AFV, Mendonça KM, Souza ACS, Pereira MS. Legislações e recomendações brasileiras relacionadas à saúde e segurança ocupacional dos trabalhadores da saúde. Rev. Eletr. Enf. [Internet]. 2017 [acesso em: ____;19:a01. Disponível em: http://dx.doi.org/10.5216/ree.v19.40427.

\section{RESUMO}

Estudo objetivou identificar e analisar as recomendações e as legislações brasileiras relacionadas ao risco biológico entre trabalhadores da área da saúde. Pesquisa documental, com busca às legislações e recomendações publicadas a partir de junho de 1978 até dezembro de 2015, mediante consulta aos documentos digitais do Ministério do Trabalho e Emprego, do Ministério da Saúde/Agência Nacional de Vigilância Sanitária e "riscobiologico.org". Foram encontradas 37 normas e legislações, sendo 25 publicadas pelo Ministério da Saúde, 10 pelo Ministério do Trabalho e Emprego e duas pelo Gabinete da Casa Civil. Os documentos analisados abrangem as diversas áreas dos serviços de saúde e trazem em seu escopo determinações específicas para a proteção do trabalhador. Conclui-se que a evolução das legislações e recomendações mostra contribuições importantes para a proteção da saúde do trabalhador e, tem agregado novas determinações advindas dos avanços científicos e tecnológicos, subsidiados pelas informações epidemiológicas.

Descritores: Pessoal de Saúde; Acidentes de Trabalho; Riscos Ocupacionais; Legislação como Assunto; Educação em Enfermagem.

\section{INTRODUÇÃO}

A saúde do trabalhador foi contemplada, efetivamente, a partir da Constituição da República Federativa do Brasil, em $1988^{(1)}$ e desde, então, busca-se construir conjuntamente, entre Ministérios da Saúde e do Trabalho e Previdência Social, políticas públicas acerca de medidas de proteção para o trabalhador. 
No contexto dos trabalhadores da área da saúde houve uma preocupação com a saúde ocupacional e a literatura mundial deu maior destaque à exposição a material biológico por representar risco imediato para os trabalhadores.

Nesse período, os casos de acidentes ocupacionais envolvendo material biológico com iminente risco de contaminação e a possibilidade de soroconversão passaram a fazer parte da atenção de pesquisadores em todo o mundo ${ }^{(2-3)}$. No Brasil, as taxas desses acidentes entre trabalhadores da área da saúde, variaram de $17,0 \%{ }^{(4)} ; 58,4 \%{ }^{(5)}$ e até de $80,4 \%{ }^{(6)}$. Os dados epidemiológicos evidenciam a importância de se ter legislações e recomendações que orientem os serviços de saúde e os profissionais na atenção à saúde.

No mundo, organismos internacionais como o Centers for Disease Control and Prevention (CDC) elaborou guidelines, para orientação de gestores e trabalhadores da área da saúde (TAS) acerca das medidas pré e pós-exposição em casos de acidente ocupacional com material biológico, orientando também a adequada notificação dos $\operatorname{casos}^{(7)}$.

O número de casos notificados de HIV, Hepatites B e C, pós-exposição percutânea envolvendo material biológico, culminou em alguns avanços importantes para a saúde do trabalhador, principalmente a partir de 2000, como a utilização de dispositivos de segurança em perfurocortantes. Os Estados Unidos da América (EUA) são os pioneiros ao publicar uma Lei em 06 de novembro de 2000, a qual tornou-se obrigatório que os perfurocortantes tenham dispositivos de segurança. $\mathrm{O}$ uso desses dispositivos, associados ao envolvimento dos trabalhadores e da instituição de saúde, em práticas de trabalho mais seguras, reduziram de $66 \%$ a $88 \%$ dos acidentes envolvendo agulhas. Na França, o uso desses dispositivos de segurança mostrou redução do número de acidentes entre $83 \%$ a $89 \%{ }^{(8-10)}$.

A exemplo de outros países, o Brasil possui recomendações e legislações relacionadas à saúde do trabalhador. Em que pese grandes avanços no que se refere à legislação observa-se um distanciamento entre a lei e a sua aplicação, por vários fatores intervenientes. Conhecer a legislação é condição para se identificar os avanços existentes relacionados à segurança ocupacional e identificar as lacunas que porventura existam.

Considerando a relevância epidemiológica e social do risco biológico, e dos consequentes acidentes com exposição a material biológico, questiona-se a abrangência e o escopo das recomendações e legislações brasileiras sobre essa temática.

O estudo objetivou identificar e analisar as recomendações e as legislações brasileiras relacionadas ao risco biológico e aos acidentes com exposição a material biológico entre trabalhadores da área da saúde.

\section{MÉTODO}

Pesquisa documental, realizada a partir de um levantamento de recomendações e legislações brasileiras publicadas a partir de junho de 1978 até dezembro de 2015, relacionadas aos acidentes com material biológico entre trabalhadores da área da saúde.

As legislações referentes à saúde do trabalhador são elaboradas e fiscalizadas pelo Ministério do Trabalho e Previdência Social. Os empregados são regidos pela Consolidação das Leis do Trabalho no 
seguimento das normas regulamentadoras (NR) pelo empregador e empregado ${ }^{(11)}$.

O Ministério da Saúde também tem como uma de suas funções apresentar legislações e recomendações que devem ser seguidas em todas as áreas de sua abrangência. São publicadas Legislações e Portarias e a Agência Nacional de Vigilância Sanitária (Anvisa), que é um órgão do Ministério da Saúde, publica Resoluções da Diretoria Colegiada (RDC), as quais devem ser seguidas quando há produtos e serviços para o controle de riscos à saúde da população ${ }^{(12)}$.

A busca ocorreu por meio do acesso aos endereços eletrônicos do Ministério do Trabalho e Previdência Social, do Ministério da Saúde/Agência Nacional de Vigilância Sanitária e "riscobiologico.org". Para dirimir possíveis omissões foi realizada uma consulta, via eletrônica, aos técnicos da Agência Nacional de Vigilância Sanitária/Ministério da Saúde acerca das Resoluções de Diretoria Colegiada existentes.

Os critérios de inclusão foram: 1) leis, recomendações, Portarias, resoluções, regulamentos, decretos e manuais nacionais sobre acidente com material biológico, especificamente, ou também, àqueles que abordam medidas de biossegurança e do risco biológico nos ambientes dos serviços de saúde, entre trabalhadores da área de saúde; 2) leis, recomendações, Portarias, resoluções, regulamentos, decretos e manuais nacionais sem limite de data de publicação. Critérios de exclusão: 1) as legislações e recomendações de abrangência limitada aos Estados e Municípios.

A coleta de dados foi realizada em duas etapas. No primeiro momento, a busca e a leitura das recomendações e legislações encontradas, foi realizada por três expertises na temática de acidentes com material biológico, de forma independente. Em um segundo momento, a leitura e a análise dos documentos foi realizada pelos pesquisadores, os quais organizaram a apresentação das leis, recomendações, Portarias, resoluções, regulamentos, decretos e manuais identificados.

Os resultados foram organizados em dois quadros para facilitar a síntese das legislações, suas normalizações, atualizações e avanços. Primeiramente, a Constituição Federal, a lei orgânica da saúde e a saúde do trabalhador; em seguida, as normatizações do Ministério do Trabalho e Previdência Social e do Ministério da Saúde. Cada documento foi identificado com a sigla doc, seguida da numeração de acordo com o ano da sua publicação em ordem crescente.

\section{RESULTADOS}

Das 37 recomendações e legislações identificadas, 10 foram publicadas pelo Ministério do Trabalho e Previdência Social, 25 pelo Ministério da Saúde e duas pelo Gabinete da Casa Civil.

O Gabinete da Casa Civil publicou duas legislações que são consideradas marcos para a área da saúde, sendo a Constituição Federal de 1988, na qual apresentam as atribuições do SUS e a Lei № 8080/90, que contempla as condições para a promoção, proteção e recuperação da saúde, a organização e o funcionamento dos serviços correspondentes.

O Quadro 1 apresenta as recomendações e legislações brasileiras relacionadas à saúde e à segurança ocupacional, dos trabalhadores da área da saúde, com enfoque ao risco biológico, publicadas pelo Ministério 
do Trabalho e Previdência Social.

O Quadro 2 expõe as recomendações e legislações brasileiras produzidas pelo Ministério da saúde, relacionadas à saúde e segurança ocupacional dos trabalhadores da área da saúde, envolvendo o risco biológico. 
Quadro 1: Recomendações e legislações brasileiras, publicadas pelo Ministério do Trabalho e Previdência Social relacionada à saúde e segurança ocupacional dos trabalhadores da área da saúde, com enfoque no risco biológico.

\begin{tabular}{|c|c|c|c|}
\hline Título & Disposições & Última Atualização & Avanço obtido com as atualizações \\
\hline $\begin{array}{l}\text { Portaria no } 3.214 \text { de } 08 \text { de junho de } 1978 . \\
\frac{\text { http://www.mte.gov.br/images/Document }}{\frac{\text { os/SST/NR/NR4.pdf }}{\text { (Doc 1) }}}\end{array}$ & $\begin{array}{l}\text { NR-4 Serviços Especializados em Engenharia de Segurança e } \\
\text { em Medicina do Trabalho (SESMT). } \\
\text { Manutenção obrigatória, pelas empresas, privadas e públicas } \\
\text { que possuem trabalhadores regidos pela Consolidação das Leis } \\
\text { do Trabalho (CLT), de SESMT, para promover e proteger a } \\
\text { saúde e a integridade do trabalhador em seu local de trabalho. }\end{array}$ & $\begin{array}{c}\text { Portaria MTE n.o 128, de } \\
\text { 11/12/2009. } \\
\frac{\text { http://www.mte.gov.br/images/ }}{\text { Documentos/SST/NR/NR4.pdf }}\end{array}$ & $\begin{array}{l}\text { Quatorze Portarias trazem } \\
\text { atualizações/alterações. Todos os artigos } \\
\text { foram atualizados, considerando a } \\
\text { necessidade de adequação da NR, à evolução } \\
\text { dos métodos e ao avanço da tecnologia. }\end{array}$ \\
\hline $\begin{array}{l}\text { Portaria no } 3.214 \text { de } 08 \text { de junho de } 1978 . \\
\frac{\text { http://www.guiatrabalhista.com.br/legisla }}{\frac{\text { cao/nr/nr5.htm }}{(\operatorname{Doc} 2)}}\end{array}$ & $\begin{array}{l}\text { NR-5 Comissão Interna de Prevenção de Acidentes de } \\
\text { Trabalho (CIPA). } \\
\text { Objetiva a prevenção de acidentes e de doenças decorrentes } \\
\text { do trabalho, para a preservação da vida e a promoção da } \\
\text { saúde do trabalhador. }\end{array}$ & $\begin{array}{l}\begin{array}{l}\text { Portaria MTE n.o 247, de } \\
\text { 12/06/2011. }\end{array} \\
\frac{\text { http://www.normaslegais.com.br }}{\text { /legislacao/portariasit247_2011.h }} \\
\underline{\mathrm{tm}}\end{array}$ & $\begin{array}{l}\text { Nove Portarias trazem } \\
\text { atualizações/alterações. A maioria dos artigos } \\
\text { foi atualizada, principalmente pela Portaria } \\
\text { MTE no. 247, de 12/06/11, na qual explicita } \\
\text { como deve ser o processo eleitoral dos } \\
\text { membros da CIPA. }\end{array}$ \\
\hline $\begin{array}{l}\text { Portaria no } 3.214 \text { de } 08 \text { de junho de } 1978 . \\
\frac{\text { http://www.guiatrabalhista.com.br/legisla }}{\frac{\text { cao/nr/nr6.htm }}{(\text { Doc } 3)}}\end{array}$ & $\begin{array}{c}\text { NR-6 Equipamentos de Proteção Individual (EPI). } \\
\text { Determinações sobre os EPI, sendo que eles só podem ser } \\
\text { vendidos ou utilizados com a indicação do Certificado de } \\
\text { Autorização, do MTE. }\end{array}$ & 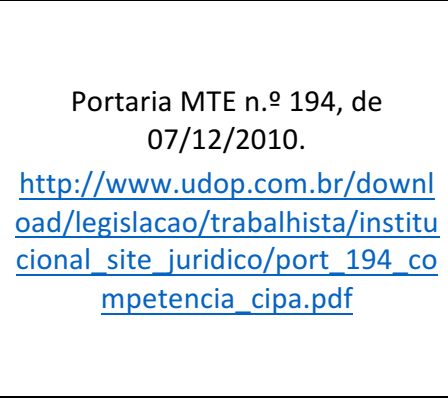 & $\begin{array}{l}\text { Dezoito Portarias trazem } \\
\text { atualizações/alterações. A maioria dos artigos } \\
\text { foi atualizada pela Portaria SIT n.o 194/07/10, } \\
\text { deixando mais abrangente as } \\
\text { responsabilidades do empregador, do } \\
\text { empregado, do fabricante e importador dos } \\
\text { EPIs. A Portaria MTE n. } 505 / 16 / 15 \text {, fez várias } \\
\text { alterações e acréscimos de itens na lista de } \\
\text { EPI, com a finalidade de aumentar a proteção } \\
\text { do trabalhador. }\end{array}$ \\
\hline $\begin{array}{l}\text { Portaria no } 3.214 \text { de } 08 \text { de junho de } 1978 . \\
\frac{\text { http://www.guiatrabalhista.com.br/legisla }}{\frac{\text { cao/nr/nr7.htm }}{(\operatorname{Doc} 4)}}\end{array}$ & $\begin{array}{l}\text { NR-7 Programa de Controle Médico em Saúde Ocupacional } \\
\text { (PCMSO). } \\
\text { "Obrigatoriedade de elaboração e implementação, por parte } \\
\text { de todos os empregadores e instituições que admitam } \\
\text { trabalhadores como empregados do PCMSO, com o objetivo } \\
\text { de promoção e preservação da saúde do conjunto dos seus } \\
\text { trabalhadores". }\end{array}$ & $\begin{array}{l}\begin{array}{l}\text { Portaria MTE n.o 1.892, de } \\
\text { 09/12/2013. }\end{array} \\
\frac{\text { http://viaseg.com.br/noticia/145 }}{56-} \\
\frac{\text { alteracao_norma_regulamentado }}{\text { ra_n_7_portaria_n_1892_de_09 }} \\
\text { _de_dezembro_de_2013.html }\end{array}$ & $\begin{array}{c}\text { Oito Portarias trazem atualizações/alterações. } \\
\text { A portaria SSST n.o 08/05/96, fez atualizações } \\
\text { em artigos como, o empregador deve custear } \\
\text { sem ônus para o empregado todos os } \\
\text { procedimentos relacionados ao PCMSO. A } \\
\text { Portaria SSST n. } 24 / 12 / 94 \text {, aprovou os } \\
\text { parâmetros para controle biológico da } \\
\text { exposição ocupacional a alguns agentes } \\
\text { químicos. }\end{array}$ \\
\hline
\end{tabular}




\begin{tabular}{|c|c|c|c|}
\hline Título & Disposições & Última Atualização & Avanço obtido com as atualizações \\
\hline $\begin{array}{l}\text { Portaria } \mathrm{n} 03.214 \text { de } 08 \text { de junho de } 1978 . \\
\frac{\text { http://www.guiatrabalhista.com.br/legisla }}{\frac{\text { cao/nr/nr9.htm }}{\text { (Doc 5) }}}\end{array}$ & $\begin{array}{l}\text { NR-9 Programa de Prevenção de Riscos Ambientais (PPRA). } \\
\text { “Obrigatoriedade da elaboração e implementação, por todos } \\
\text { os empregadores e instituições que admitam trabalhadores, } \\
\text { do PPRA, visando à preservação da saúde e da integridade dos } \\
\text { trabalhadores, através da antecipação, reconhecimento, } \\
\text { avaliação e consequente controle da ocorrência de riscos } \\
\text { ambientais ou que venham a existir no trabalho, tendo em } \\
\text { consideração a proteção do meio ambiente e dos recursos } \\
\text { naturais". }\end{array}$ & $\begin{array}{c}\begin{array}{c}\text { Portaria MTE n.o 1.471, de } \\
24 \text { de setembro de } 2014\end{array} \\
\frac{\text { http://acesso.mte.gov.br/data/fil }}{\text { es/FF80808148EC2E5E014961B2 }} \\
\frac{553368 \text { F0/Portaria\%20n.\%C2\%BA }}{\frac{\text { \%201471\%20(Certifica\%C3\%A7\% }}{\text { C3\%A30\%20de\%20Pessoas\%20- }}} \\
\underline{20 \text { prorroga\%20-\%20NR-35).pdf }}\end{array}$ & $\begin{array}{l}\text { Três Portarias que trazem } \\
\text { alterações/atualizações, principalmente pela } \\
\text { Portaria SSST n.o 25/12/94, a qual seguindo } \\
\text { determinações da OIT, apresenta melhores } \\
\text { orientações sobre a adoção de mediadas para } \\
\text { o controle de riscos ambientais, nos locais de } \\
\text { trabalho, com a inclusão de Mapa de Riscos. }\end{array}$ \\
\hline $\begin{array}{l}\text { Portaria no } 3.214 \text { de } 08 \text { de junho de } 1978 . \\
\frac{\text { http://www.guiatrabalhista.com.br/legisla }}{\frac{\text { cao/nr/nr15.htm }}{\underline{\text { (Doc 6) }}}}\end{array}$ & $\begin{array}{l}\text { NR-15 Atividades e operações insalubres. } \\
\text { Considera as atividades ou operações insalubres, o que pela } \\
\text { avaliação do risco vai assegurar ao trabalhador a percepção de } \\
\text { adicional, incidente sobre o salário mínimo definido. }\end{array}$ & $\begin{array}{c}\text { Portaria MTE n.o 203, de } \\
\text { 28/01/2011. } \\
\frac{\text { http://www.ccb.usp.br/arquivos/ }}{\text { arqpessoal/1360237303_nr15atu }} \\
\text { alizada2011ii.pdf }\end{array}$ & $\begin{array}{c}\text { Dezessete Portarias trazem } \\
\text { atualizações/alterações. A Port. SSST-12/79 } \\
\text { aprova a relação de atividades que envolvam } \\
\text { agentes biológicos, classificando a } \\
\text { insalubridade em grau máximo e médio. }\end{array}$ \\
\hline $\begin{array}{l}\text { Portaria Gabinete Ministro n.․ 485, de } 11 \\
\text { de novembro de } 2005 . \\
\underline{\text { http://www.guiatrabalhista.com.br/legisla }} \\
\underline{\text { cao/nr/nr32.htm }}\end{array}$ & $\begin{array}{l}\text { NR-32 Segurança e saúde no trabalho em serviços de saúde. } \\
\text { "Estabelecer as diretrizes básicas para a implementação de } \\
\text { medidas de proteção à segurança e à saúde dos trabalhadores } \\
\text { dos serviços de saúde, e daqueles que exercem atividades de } \\
\text { promoção e assistência à saúde em geral". }\end{array}$ & $\begin{array}{c}\text { Portaria MTE n.o 1.748, de } \\
\text { 30/08/2011. } \\
\frac{\text { http://www.normaslegais.com.br }}{\frac{\text { /legislacao/portaria-mte-1748- }}{\frac{2011 . h t m}{\underline{\text { Doc 7) }}}}}\end{array}$ & $\begin{array}{c}\text { Altera o subitem 32.2.4.16 da NR no 32, } \\
\text { instituindo o Plano de Prevenção de Riscos de } \\
\text { Acidentes com Materiais Perfurocortantes, } \\
\text { alterando a redação. }\end{array}$ \\
\hline $\begin{array}{l}\text { Manual:Risco Biológico:Guia técnico. } 2008 . \\
\frac{\text { http://acesso.mte.gov.br/data/files/FF808 }}{\text { 0812BCB2790012BD509161913AB/guia_te }} \\
\text { cnico_cs3.pdf }\end{array}$ & $\begin{array}{l}\text { Risco Biológico: Guia técnico. } \\
\text { Informações a trabalhadores, empregadores e técnicos da } \\
\text { área da saúde, para um maior entendimento dos artigos } \\
\text { referentes aos Riscos Biológicos, presentes na NR 32/05. }\end{array}$ & - & \\
\hline $\begin{array}{l}\text { Manual de Implementação do Programa de } \\
\text { Prevenção de Acidentes com Material } \\
\text { Perfurocortantes em Serviços de Saúde. } \\
\text { Ano: } 2010 . \\
\frac{\text { http://www.fundacentro.gov.br/biblioteca }}{\text { /bibliotecadigital/publicacao/detalhe/2012 }} \\
\frac{\text { /9/manual-de-implementacao-programa- }}{\text { de-prevencao-de-acidentes-com-materiais- }} \\
\text { perfurocortantes-em }\end{array}$ & $\begin{array}{l}\text { Implementação do Programa de Prevenção de Acidentes com } \\
\text { Material Perfurocortantes em Serviços de Saúde. Ano: } 2010 . \\
\text { Orientações aos serviços de saúde na elaboração, } \\
\text { implementação e avaliação do seu programa de prevenção de } \\
\text { acidentes com perurocortantes. Auxilia também, no } \\
\text { atendimento das exigências legais da NR 32/05. }\end{array}$ & - & \\
\hline $\begin{array}{l}\text { Portaria no } 1748 \text { de } 30 \text { de agosto de } 2011 . \\
\frac{\text { http://www.sbpc.org.br/upload/conteudo/ }}{320110926145339 . p d f}\end{array}$ & $\begin{array}{l}\text { Orientações para elaboração e implementação do Plano de } \\
\text { Prevenção de Riscos de Acidentes com Materiais } \\
\text { Perfurocortantes, alterando o subitem 32.2.4.16 da NR n.o } 32 \text {. }\end{array}$ & - & \\
\hline
\end{tabular}


Quadro 2: Recomendações e legislações brasileiras, publicadas pelo Ministério da Saúde, relacionadas à saúde e segurança ocupacional

dos trabalhadores da área da saúde com enfoque no risco biológico.

\begin{tabular}{|c|c|c|c|}
\hline Título & Disposições & Atualização & Avanço obtido com a atualização \\
\hline $\begin{array}{l}\text { Portaria no } 777 \text { de } 28 \text { de abril de } 2004 . \\
\text { http://www.cerest.piracicaba.sp.gov.br/sit } \\
\text { e/images/Portaria_777_-NOTIFICAO.pdf }\end{array}$ & $\begin{array}{l}\text { Dispõe sobre os procedimentos técnicos para a notificação } \\
\text { compulsória de agravos à saúde do trabalhador em rede de } \\
\text { serviços sentinela específica, no Sistema Único de Saúde - } \\
\text { SUS. } \\
\text { Regulamentou a notificação compulsória de agravos à saúde } \\
\text { do trabalhador }\end{array}$ & $\begin{array}{l}\text { Portaria no 1.271, de 6/06/2014. } \\
\frac{\text { http://bvsms.saude.gov.br/bvs/s }}{\text { audelegis/gm/2014/prt1271_06_- }} \\
\frac{06 \_2014 . h t m l}{\text { (Doc 11) }}\end{array}$ & $\begin{array}{l}\text { Acrescentou à lista nacional de notificação } \\
\text { compulsória, o acidente de trabalho com } \\
\text { exposição a material biológico. }\end{array}$ \\
\hline $\begin{array}{l}\text { Portaria no } 2616 \text { de } 12 \text { de maio de } 1998 . \\
\frac{\text { http://bvsms.saude.gov.br/bvs/saudelegis/ }}{\text { gm/1998/prt2616_12_05_1998.html }} \\
\text { (Doc 8) }\end{array}$ & $\begin{array}{l}\text { Comissão de Controle de Infecção Hospitalar. } \\
\text { Diretrizes e normas para a prevenção e o controle das } \\
\text { infecções, finalizando a maior redução possível da incidência e } \\
\text { gravidade das infecções nos hospitais. Medidas para } \\
\text { prevenção de infecções visando evitar a disseminação de } \\
\text { microrganismos para os pacientes e para o trabalhador. }\end{array}$ & - & \\
\hline $\begin{array}{c}\text { Manual: Biossegurança em Saúde: } \\
\text { prioridades e estratégias de ação. } 2010 \\
\frac{\text { http://bvsms.saude.gov.br/bvs/publicacoe }}{\text { s/biosseguranca_saude_prioridades_estrat }} \\
\frac{\text { egicas_acao_p1.pdf }}{\underline{\text { (Doc 9) }}}\end{array}$ & $\begin{array}{l}\text { Biossegurança em Saúde. } \\
\text { Sistematização de discussões para elaborar um consenso a ser } \\
\text { pactuado, sobre princípios, diretrizes e objetivos nacionais } \\
\text { sobre biossegurança em saúde. }\end{array}$ & - & \\
\hline $\begin{array}{l}\text { RDC no } 306 \text { de } 7 \text { de dezembro de } 2004 . \\
\frac{\text { http://www.saude.mg.gov.br/images/docu }}{\frac{\text { mentos/res_306.pdf }}{\text { (Doc 10) }}}\end{array}$ & $\begin{array}{l}\text { Dispõe sobre o gerenciamento de resíduos em serviços de } \\
\text { saúde. } \\
\text { Classifica os resíduos nos grupos A, B, C, D, E e orienta sobre a } \\
\text { elaboração de Plano de Gerenciamento de Resíduos. }\end{array}$ & - & \\
\hline $\begin{array}{l}\text { Portaria no } 1.823 \text { de } 23 \text { de agosto de } 2012 . \\
\frac{\text { http://bvsms.saude.gov.br/bvs/saudelegis/ }}{\text { gm/2012/prt1823_23_08_2012.html }} \\
\underline{\text { (Doc 12) }}\end{array}$ & $\begin{array}{l}\text { Instituiu a Política Nacional de Saúde do Trabalhador e da } \\
\text { Trabalhadora. } \\
\text { Princípios, diretrizes e estratégias observados pelas três } \\
\text { esferas de gestão do SUS, para o desenvolvimento da atenção } \\
\text { integral à saúde do trabalhador. Ênfase na vigilância, visando } \\
\text { promoção e proteção da saúde dos trabalhadores e redução } \\
\text { da morbimortalidade proveniente dos processos produtivos. }\end{array}$ & - & \\
\hline
\end{tabular}




\begin{tabular}{|c|c|c|c|}
\hline Título & Disposições & Atualização & Avanço obtido com a atualização \\
\hline $\begin{array}{l}\text { RDC } n \text { o 2, de } 25 \text { de janeiro de } 2010 . \\
\frac{\text { http://bvsms.saude.gov.br/bvs/saudelegis/ }}{\text { anvisa/2010/res0002_25_01_2010.html }} \\
\underline{\text { (Doc 13) }}\end{array}$ & $\begin{array}{l}\text { Dispõe sobre o gerenciamento de tecnologias em saúde em } \\
\text { estabelecimentos de saúde. } \\
\text { Critérios mínimos a serem seguidos pelos serviços de saúde, } \\
\text { quanto ao gerenciamento de tecnologias a serem utilizadas na } \\
\text { prestação de serviços à população, desde a entrada no } \\
\text { estabelecimento até o destino final. Indica o uso de EPI para a } \\
\text { proteção a riscos que possam ameaçar a saúde e a segurança } \\
\text { no trabalho. }\end{array}$ & $\begin{array}{l}\text { RDC no. } 20 \text { de } 23 / 03 / 2012 . \\
\frac{\text { https://www.google.com.br/?gw }}{\text { s_rd=ssl\#q=RDC+n\%C2\%BA.+20+ }} \\
\frac{\text { de+23\%2F03\%2F2012+gerenciam }}{\text { ento+de+tecnologias }}\end{array}$ & $\begin{array}{l}\text { Alterações na redação do } \S 1 \text { o do artigo } 6 \text { o e o } \\
\text { artigo } 16 \text { da RDC no. } 225 / 01 / 10 \text {, eliminando } \\
\text { as orientações do Guia de Gerenciamento de } \\
\text { Tecnologias em Saúde e exclui o artigo } 22 \text {. }\end{array}$ \\
\hline $\begin{array}{l}\text { RDC no } 7 \text { de } 24 \text { de fevereiro de } 2010 \\
\frac{\text { http://bvsms.saude.gov.br/bvs/saudelegis/ }}{\text { anvisa/2010/res0007_24_02_2010.html }} \\
\text { (Doc 14) }\end{array}$ & $\begin{array}{l}\text { Dispõe sobre os requisitos mínimos para funcionamento de } \\
\text { Unidades de Terapia Intensiva (UTI). } \\
\text { Redução de riscos aos pacientes, visitantes, trabalhadores e } \\
\text { meio ambiente. }\end{array}$ & $\begin{array}{l}\text { RDC } \mathrm{n} \text {-. } 26 \text { de 11/05/2012. } \\
\frac{\text { http://bvsms.saude.gov.br/bvs/s }}{\text { audelegis/anvisa/2012/rdc0026 }} \\
\underline{11 \text { 05_2012.html }}\end{array}$ & $\begin{array}{l}\text { Altera o inciso III e } \mathrm{V} \text { do artigo } 14, \\
\text { determinando, a relação do número de } \\
\text { enfermeiros e técnicos por leito por turno }\end{array}$ \\
\hline $\begin{array}{c}\text { RDC no } 15 \text { de 15/03/ } 2012 . \\
\frac{\text { http://www.abih.net.br/wp- }}{\frac{\text { content/uploads/RDC-15- }}{\text { ANVISA_Processamento-Artigos- }}} \\
\frac{\text { 15Mar2012.pdf }}{\underline{\text { (Doc 15) }}}\end{array}$ & $\begin{array}{l}\text { Dispõe sobre requisitos de boas práticas para } \\
\text { o processamento de produtos para saúde. } \\
\text { Boas práticas para o funcionamento de serviços que realizam } \\
\text { o processamento de produtos para a saúde, para garantir a } \\
\text { segurança do paciente e do trabalhador. }\end{array}$ & & \\
\hline $\begin{array}{l}\text { Manual de Condutas: exposição } \\
\text { Ocupacional a Material Biológico: Hepatite } \\
\text { e HIV. } 2000 . \\
\text { http://bvsms.saude.gov.br/bvs/publicacoe } \\
\text { s/manual_condutas_hepatite_hiv.pdf }\end{array}$ & $\begin{array}{c}\text { Condutas que devem ser adotadas em caso se exposição do } \\
\text { trabalhador a material biológico } \\
\text { O objetivo do manual é oferecer informações sobre como } \\
\text { proceder para evitar a disseminação ocupacional dos vírus HIV } \\
\text { e Hepatites B e C. }\end{array}$ & $\begin{array}{l}\text { Manual: Recomendações para } \\
\text { atendimento e acompanhamento } \\
\text { de exposição ocupacional a } \\
\text { material biológico: HIV e } \\
\text { Hepatites B e C. Ano: } 2004 \text {. } \\
\frac{\text { http://www.aids.gov.br/publicac }}{\frac{\text { ao/2004/recomendacoes-para- }}{\text { atendimento-e- }}} \\
\frac{\text { acompanhamento-de-exposicao- }}{\text { ocupacional-material-bi }}\end{array}$ & $\begin{array}{c}\text { Atualização do manual publicado no ano de } \\
\text { 2000. Inovações em tratamento e ampliação } \\
\text { da vacina de hepatite B a pessoas de todas as } \\
\text { idades, independente de vulnerabilidades } \\
\text { específicas. }\end{array}$ \\
\hline $\begin{array}{l}\text { Portaria Conjunta Agência Nacional de } \\
\text { Vigilância Sanitária/Funasa no 01, de } 02 \text { de } \\
\text { Agosto de } 2000 . \\
\frac{\text { http://www.rio.rj.gov.br/dlstatic/10112/37 }}{\frac{40546 / 4106738 / \text { Portariaconjunta01ANVIS }}{\text { AFUNASA.pdf }}}\end{array}$ & $\begin{array}{l}\text { Exigências para o funcionamento de estabelecimentos } \\
\text { privados de vacinação, seu licenciamento, fiscalização e } \\
\text { controle, e dá outras providências. Determina o descarte dos } \\
\text { perfurocortantes em recipientes adequados, para a } \\
\text { prevenção de acidente envolvendo material biológico. }\end{array}$ & - & \\
\hline
\end{tabular}




\begin{tabular}{|c|c|c|c|}
\hline Título & Disposições & Atualização & Avanço obtido com a atualização \\
\hline $\begin{array}{l}\text { RDC no 45, de 12/03/2003. } \\
\frac{\text { http://www20.anvisa.gov.br/segurancadop }}{\text { aciente/index.php/legislacao/item/resoluc }} \\
\frac{\text { ao-rdc-n-45-de-12-de-marco-de-2003 }}{}\end{array}$ & $\begin{array}{l}\text { Dispõe sobre o regulamento técnico de boas práticas de } \\
\text { utilização de soluções parenterais em serviço de saúde. } \\
\text { Requisitos mínimos para a utilização de soluções parenterais, } \\
\text { garantindo sua segurança e eficácia. Instituição do Programa } \\
\text { de Controle Médico de Saúde Ocupacional (PCMSO), } \\
\text { estabelecido pela NR 07, do MTPS e conhecimento do } \\
\text { trabalhador sobre segurança no trabalho. }\end{array}$ & - & \\
\hline $\begin{array}{l}\text { RDC no } 154 \text { de 15/06/2004. Revogada } \\
\frac{\text { http://www.saude.mt.gov.br/upload/contr }}{\text { ole- }} \\
\frac{\text { infeccoes/pasta9/resolucao_rdc_n154_200 }}{\text { 4_regulamento_servicos_dialise.pdf }}\end{array}$ & $\begin{array}{l}\text { Estabelece o Regulamento Técnico para o } \\
\text { funcionamento dos Serviços de Diálise }\end{array}$ & $\begin{array}{l}\begin{array}{r}\text { RDC } \mathrm{n}^{\circ} \text { 11, de } 13 / 03 / 2014 \text { e RDC } \\
\text { no } 36 \text { de 16/06/2014 }\end{array} \\
\frac{\text { http://bvsms.saude.gov.br/bvs/s }}{\text { audelegis/anvisa/2014/rdc0011 }} \\
\frac{13 \text { 03_2014.pdf }}{\underline{\text { Doc } 16)}}\end{array}$ & $\begin{array}{c}\text { Revogou a RDC no. 154/2004. } \\
\text { Obrigatório o descarte dos dialisadores e } \\
\text { linhas utilizadas em pacientes com hepatites B } \\
\text { e C e todas as linhas utilizadas nos } \\
\text { procedimentos hemodialíticos. } \\
\text { Acompanhamento e realização de exames } \\
\text { periódicos a pacientes em estágios iniciais da } \\
\text { doença. }\end{array}$ \\
\hline $\begin{array}{l}\text { Manual: recomendações para atendimento } \\
\text { e acompanhamento } \\
\text { de exposição ocupacional a material } \\
\text { biológico: HIV e } \\
\text { Hepatites B e C. } 2004 \text {. } \\
\frac{\text { http://bvsms.saude.gov.br/bvs/publicacoe }}{\text { s/04manual_acidentes.pdf }}\end{array}$ & $\begin{array}{l}\text { Recomendações para atendimento e acompanhamento de } \\
\text { exposição ocupacional a material biológico: HIV e Hepatites B } \\
\text { e C. }\end{array}$ & $\begin{array}{c}\begin{array}{c}\text { Manual exposição a Materiais } \\
\text { Biológicos. } 2006\end{array} \\
\frac{\text { http://bvsms.saude.gov.br/bvs/p }}{\text { ublicacoes/protocolo_expos_mat }} \\
\text { _biologicos.pdf }\end{array}$ & $\begin{array}{l}\text { Reforça as condutas adotadas no Manual de } \\
\text { 2004, organiza os parâmetros a serem } \\
\text { seguidos pelos serviços de saúde e estabelece } \\
\text { fluxo para o atendimento ao acidentado e a } \\
\text { fonte do acidente. }\end{array}$ \\
\hline $\begin{array}{l}\text { RDC no 302, de 13/10/2005. } \\
\frac{\text { http://www20.anvisa.gov.br/segurancadop }}{\frac{\text { aciente/index.php/legislacao/item/rdc- }}{\text { 302-de-13-de-outubro-de-2005 }}}\end{array}$ & $\begin{array}{l}\text { Regulamento Técnico para funcionamento de Laboratórios } \\
\text { Clínicos. } \\
\text { Funcionamento do laboratório clínico e posto de coleta } \\
\text { laboratorial e assegurar a qualidade dos exames laboratoriais. } \\
\text { Vacinação de todos os trabalhadores de acordo com a } \\
\text { legislação vigente, instituição do PCMSO, conforme } \\
\text { determinações da NR 07/MTPS e orientação dos trabalhadores } \\
\text { sobre biossegurança. }\end{array}$ & $\begin{array}{c}\text { RDC no. } 30 \text { de 24/07/2015. } \\
\frac{\text { http://sbac.org.br/wpcontent/upl }}{\underline{\text { oads/2016/01/RDC_30.pdf }}}\end{array}$ & $\begin{array}{c}\text { Altera a redação do item } 6.3 .2 \text { da } \mathrm{RDC} \text { n. } 0302 \\
\text { de } 03 / 10 / 05, \text { referente à garantia da } \\
\text { autenticidade e a integridade do laudo } \\
\text { emitido. }\end{array}$ \\
\hline $\begin{array}{c}\text { RDC no 171, de 04/09/2006. } \\
\frac{\text { http://crn3.org.br/Areas/Admin/Content/u }}{\underline{\text { pload/file-0711201565917.pdf }}}\end{array}$ & $\begin{array}{l}\text { Dispõe sobre o regulamento técnico para o funcionamento de } \\
\text { bancos de leite humano. } \\
\text { Constitui uma medida eficaz para as políticas públicas de } \\
\text { amamentação. Determinações da utilização do EPI em } \\
\text { conformidade com a atividade a ser desenvolvida. }\end{array}$ & - & \\
\hline
\end{tabular}




\begin{tabular}{|c|c|c|c|}
\hline Título & Disposições & Atualização & Avanço obtido com a atualização \\
\hline $\begin{array}{l}\text { RDC no 36, de 03/06/2008. } \\
\frac{\text { http://www20.anvisa.gov.br/segurancadop }}{\text { aciente/index.php/legislacao/item/rdc-n- }} \\
\text { 36-de-03-de-junho-de-2008 }\end{array}$ & $\begin{array}{l}\text { Dispõe sobre o regulamento técnico para o funcionamento } \\
\text { dos serviços de atenção obstétrica e neonatal. } \\
\text { O funcionamento dos serviços deve ser baseado na } \\
\text { qualificação, na humanização da atenção e na redução e } \\
\text { controle de riscos aos usuários e meio ambiente. O serviço } \\
\text { deverá manter normas e rotinas escritas de biossegurança, } \\
\text { atualizadas e disponíveis aos trabalhadores, que contemplem } \\
\text { o uso de EPI e equipamentos de proteção coletiva e, condutas } \\
\text { em caso de acidentes, dentre outros aspectos. }\end{array}$ & - & \\
\hline $\begin{array}{l}\text { Manual exposição a Materiais Biológicos. } \\
\text { Ano } 2006 \\
\frac{\text { http://bvsms.saude.gov.br/bvs/publicacoe }}{\text { s/protocolo_expos_mat_biologicos.pdf }}\end{array}$ & $\begin{array}{l}\text { Exposições a material biológico } \\
\text { Orientações para o atendimento ao trabalhador vítima de } \\
\text { acidente envolvendo material biológico, com risco a } \\
\text { soroconversão aos vírus HIV e das hepatites B e C. }\end{array}$ & $\begin{array}{l}\begin{array}{r}\text { Exposição a Materiais Biológicos. } \\
2011\end{array} \\
\begin{array}{l}\text { http://www.saude.rs.gov.br/uplo } \\
\frac{\text { ad/1337000719_Exposi\%C3\%A7 }}{\% \text { C3\%A30\%20a\%20Materiais\%20 }} \\
\text { Biol\%C3\%B3gicos.pdf }\end{array}\end{array}$ & Reedição do Manual de 2006. \\
\hline $\begin{array}{l}\begin{array}{l}\text { Manual: Exposição a Materiais Biológicos. } \\
\text { Ano } 2011 .\end{array} \\
\frac{\text { http://www.saude.rs.gov.br/upload/13370 }}{\text { 00719_Exposi\%C3\%A7\%C3\%A3o\%20a\%20 }} \\
\text { Materiais\%20Biol\%C3\%B3gicos.pdf }\end{array}$ & $\begin{array}{l}\text { Exposição a Materiais Biológicos } \\
\text { Condutas para o atendimento ao trabalhador vítima de } \\
\text { acidente com material biológico. }\end{array}$ & & \\
\hline $\begin{array}{l}\text { Manual de Recomendações para Terapia } \\
\text { Antirretroviral em Adultos } \\
\text { Infectados pelo HIV publicado em 2010. } \\
\text { http://www.aids.gov.br/sites/default/files/ } \\
\frac{\text { publicacao/2007/suplemento_consenso_a }}{\text { dulto_01_24_01_2011_web_pdf_13627.pd }} \\
\frac{\text { f }}{}\end{array}$ & $\begin{array}{l}\text { O Protocolo Clínico e Diretrizes Terapêuticas de PEP. } \\
\text { Atualizações na profilaxia pós-exposição ocupacional ao HIV e } \\
\text { na norma Técnica sobre violência sexual. }\end{array}$ & $\begin{array}{c}\text { Manual: protocolo clínico e } \\
\text { diretrizes terapêuticas para } \\
\text { profilaxia antirretroviral pós- } \\
\text { exposição de risco à infecção pelo } \\
\text { HIV. } 2015 \text {. } \\
\frac{\text { http://www.aids.gov.br/publicac }}{\text { ao/2015/protocolo-clinico-e- }} \\
\text { profilaxia-antirretroviral-pos-ex-0 } \\
\text { priarerapeuticas-para- }\end{array}$ & $\begin{array}{l}\text { Extinção das categorias de PEP; recomendação } \\
\text { de um único esquema de antirretrovirais para } \\
\text { todos os tipos de acidentes, que devem ser } \\
\text { iniciados em até } 72 \text { horas, após a exposição ao } \\
\text { HIV durante } 28 \text { dias; teste rápido para HIV } \\
\text { para o indivíduo exposto e redução do tempo } \\
\text { de acompanhamento. }\end{array}$ \\
\hline $\begin{array}{c}\text { RDC no } 63 \text { de 25/11/2011. } \\
\frac{\text { http://www20.anvisa.gov.br/segurancadop }}{\frac{\text { aciente/index.php/legislacao/item/rdc-63- }}{\text { de-25-de-novembro-de-2011 }}}\end{array}$ & $\begin{array}{l}\text { Dispõe sobre os Requisitos de Boas Práticas de Funcionamento } \\
\text { para os Serviços de Saúde. } \\
\text { O funcionamento dos serviços de saúde deve ser baseado na } \\
\text { humanização, qualificação, redução e controle de riscos aos } \\
\text { usuários e meio ambiente. Estabelece a proteção à saúde do } \\
\text { trabalhador, com o uso de EPI, imunização e a comunicações } \\
\text { de acidentes de trabalho (CAT). Essa norma soma-se às } \\
\text { determinações da NR 32, do MTPS. }\end{array}$ & - & \\
\hline
\end{tabular}




\begin{tabular}{|c|c|c|c|}
\hline Título & Disposições & Atualização & Avanço obtido com a atualização \\
\hline $\begin{array}{c}\text { Decreto no } 7.508 \text { de 28/06/2011 } \\
\frac{\text { http://www.planalto.gov.br/ccivil_03/_ato }}{\underline{\text { 2011-2014/2011/decreto/D7508.htm }}}\end{array}$ & $\begin{array}{c}\text { Regulamenta a Lei n⿳0 } 8.080 / 90 \text {, sobre a organização do SUS, o } \\
\text { planejamento, a assistência à saúde e a articulação } \\
\text { interfederativa. Garante as determinações referentes à } \\
\text { segurança e a saúde do trabalhador. }\end{array}$ & - & \\
\hline $\begin{array}{l}\text { RDC no } 6 \text { de 30/01/2012 } \\
\frac{\text { http://bvsms.saude.gov.br/bvs/saudelegis/ }}{\text { anvisa/2012/rdc0006_30_01_2012.html }}\end{array}$ & $\begin{array}{l}\text { Dispõe sobre as Boas Práticas de Funcionamento para as } \\
\text { Unidades de Processamento de Roupas de Serviços de Saúde. } \\
\text { Garantia de lavatórios de mãos com os insumos necessários à } \\
\text { higienização das mãos, disponibilização de EPI, orientações } \\
\text { quanto ao gerenciamento de resíduos e condutas a serem } \\
\text { adotadas em caso de acidentes de trabalho. }\end{array}$ & - & \\
\hline $\begin{array}{l}\text { RDC no } 6 \text { de 01/03/2013. } \\
\frac{\text { http://www.saude.mt.gov.br/upload/contr }}{\text { ole-infeccoes/pasta2/rdc-n-6-2013-serv- }} \\
\text { endoscopia.pdf }\end{array}$ & $\begin{array}{l}\text { Dispõe sobre os requisitos de Boas Práticas de Funcionamento } \\
\text { para os serviços de endoscopia com via de acesso ao } \\
\text { organismo por orifícios exclusivamente naturais. Capítulo } \\
\text { exclusivo sobre segurança e saúde no trabalho. Exigência do } \\
\text { registro de acidentes ocupacionais, orientação sobre o uso de } \\
\text { EPI e o reforço quanto a higienização das mãos }\end{array}$ & - & \\
\hline $\begin{array}{l}\text { RDC no } 20 \text { de 10/04/2014. } \\
\frac{\text { http://www.saude.pr.gov.br/arquivos/File/ }}{\text { RDC_20_de_10_de_abril_2014_Transporte }} \\
\text { _de_material_Biologico.pdf }\end{array}$ & $\begin{array}{l}\text { Dispõe sobre regulamento sanitário para o transporte de } \\
\text { material biológico humano. O remetente, transportador e } \\
\text { destinatário do material biológico deverão adotar medidas de } \\
\text { biossegurança, assim como o trabalhador envolvido em cada } \\
\text { etapa do processo de transporte. }\end{array}$ & $\begin{array}{c}\begin{array}{c}\text { RDC no. } 30 \text { de } 23 / 05 / 2014 . \\
\text { http://www.sbpc.org.br/upload/c }\end{array} \\
\frac{\text { onteudo/anvisa_rdc30_23maio20 }}{\underline{14 . p d f}}\end{array}$ & $\begin{array}{l}\text { Alterou o art. } 44 \text { da } \mathrm{RDC} \text { no } 20 / 14 \text {, ampliando } \\
\text { o prazo de } 30 \text { para } 180 \text { dias para cumprimento } \\
\text { da resolução. }\end{array}$ \\
\hline
\end{tabular}




\section{DISCUSSÃO}

Grandes marcos históricos conhecidos sobre saúde e segurança no trabalho aconteceu com a promulgação da Constituição de $1988^{(1)}$, sendo eles, a Constituição Federal e a Lei Orgânica da Saúde que possuem em seus escopos determinações para a saúde do trabalhador.

Com a Constituição Federal ${ }^{(1)}$, as deliberações acerca da saúde do trabalhador foram formalizadas, iniciando uma interlocução com a sociedade de forma mais efetiva. Além disso, sua promulgação determinou que as políticas sociais e econômicas desenvolvessem ações e serviços públicos de modo a integrarem uma rede regionalizada e hierarquizada para redução dos agravos à saúde. Por meio dessa Constituição, o brasileiro tem a sua saúde assegurada pelas ações de promoção, proteção e recuperação de maneira universal e igualitária ${ }^{(1)}$.

Outro grande avanço foi a criação de um sistema de saúde unificado com competências que incluíram a vigilância em saúde do trabalhador e também, a formação de recursos humanos ${ }^{(1)}$. Esse sistema, denominado, Sistema Único de Saúde foi regulamentado pela Lei № 8080/90, a qual incluiu o trabalhador em seu campo de atuação, sendo respaldado por todas as esferas governamentais. Ela assegura a assistência à recuperação e reabilitação dos trabalhadores vítimas de acidentes de trabalho ou portador de doenças profissionais e laborais. Essa normativa estabelece que o trabalhador tenha o direito de ser informado sobre os riscos e doenças associadas ao trabalho, participar em normatização, fiscalização e controle dos serviços de saúde do trabalhador em instituições públicas e privadas, dentre outras garantias, a fim de evitar acidentes $^{(13)}$.

As recomendações e legislações sobre a saúde do trabalhador estão sujeitas a frequentes revogações, emendas e a diversas atualizações dos documentos seguindo recomendações da Organização Mundial da Saúde (OMS) e Organização Pan Americana da Saúde (OPAS) e também da Safety and Health Administration Ocupacional (OSHA), nos Estados Unidos da América, que elaboram Legislações e Recomendações aplicadas aos empregadores e empregados. Como exemplo, a utilização de equipamentos de proteção individual (EPI) como medida protetora à exposição ocupacional a sangue ou outros materiais potencialmente infecciosos ${ }^{(14-}$ 15).

A elaboração da NR-4, de 08 de junho de 1978, atualizada em 2014 determina a instituição do Serviço Especializado em Engenharia e em Medicina do Trabalho (SESMT) com a finalidade de promover a saúde e proteger a integridade do trabalhador no local de trabalho (doc 1). A NR-5, de 08 de junho de 1978, atualizada em 2011, tornou obrigatória a criação de uma Comissão Interna de Prevenção de Acidentes (CIPA) visando prevenir acidentes e doenças decorrentes do trabalho, incluindo aqueles que envolvam material biológico (doc 2).

Tanto o SESMT quanto a CIPA abordam questões referentes ao empregador e ao empregado, como caminhos para proteção da saúde dos trabalhadores da área da saúde. Importante destaque é a determinação ao empregador de disponibilizar, gratuitamente e em perfeito estado de conservação e de funcionamento, EPI adequado ao risco existente em determinada atividade, assegurando as determinações 
da NR-6, 08 de junho de 1978, atualizada em 2011 (doc 3).

Dados provenientes do SESMT orientam os gerentes de serviços de saúde na elaboração de medidas de prevenção e de controle de acidentes de trabalho com exposição a material biológico ${ }^{(16)}$.

O controle da saúde dos trabalhadores da área da saúde é obrigatório em todo serviço de saúde, sendo instituído o Programa de Controle Médico de Saúde Ocupacional, de acordo com os riscos a que os trabalhadores se expõem, conforme estabelecido pela NR-7, 29 de dezembro de 1994, atualizada em 2013 (doc 4). Esse programa deve ter articulação com todas as normas regulamentadoras, em especial, com o Programa de Prevenção de Riscos Ambientais da NR-9, 08 de junho de 1978, atualizada em 2014 (doc 5), sendo o SESMT o responsável pelos dois programas.

O trabalho em serviços de saúde recebe destaque na NR-15, de 08 de junho de 1978, atualizada em 2014, que apresenta a relação das atividades com insalubridade sobressaindo aquelas que envolvem agentes biológicos, cuja insalubridade é de grau médio ou máximo (doc 6). Importante destaque se faz à modificação do subitem 32.2.4.16 da NR-32, que determina ao empregador elaborar e implementar o Plano de Prevenção de Riscos de Acidentes com materiais perfurocortantes, informando que as empresas que comercializam esses materiais são responsáveis por disponibilizar a capacitação sobre a correta utilização do dispositivo de segurança, aos trabalhadores de serviços de saúde (doc 7).

A publicação do Ministério do Trabalho e Previdência Social foi fundamental, em 2010, ao propor em um manual orientador a implementação do programa de prevenção de acidentes com materiais perfurocortantes em serviços de saúde, em atenção à preocupação com os riscos de acidente com material biológico, envolvendo perfurocortantes ${ }^{(17)}$.

De forma conjunta com o Ministério do Trabalho e Previdência Social, as normas e as legislações do Ministério da Saúde, colaboram para fortalecer as políticas sobre a saúde do trabalhador. Essas se fortaleceram com a criação da Anvisa, em 1984, órgão cujas ações contribuem para a prevenção e controle de agravos à saúde.

Uma das principais e pioneiras normativas do Ministério da Saúde sobre o tema risco biológico foi a Portaria no 2.616, do ano de 1998 e que ainda está vigente. Ela traz recomendações e medidas a serem adotadas na área da saúde que refletem em maior segurança para o trabalhador e para o paciente, como a adesão à técnica de higienização das mãos e o uso de equipamentos de proteção (doc 10). Assim, mesmo de forma indireta, a Portaria trata de medidas protetivas aos acidentes de trabalho com exposição a material biológico (doc 8).

Nesse mesmo sentido, o Ministério da Saúde, em parceria com a Organização Pan Americana da Saúde desenvolveu estudos sobre risco biológico, indicando condutas que devem ser adotadas pelos trabalhadores da área da saúde e seus empregadores, incluindo questões referentes ao monitoramento do risco biológico, potenciais impactos e capacidade no manuseio de agentes biológicos na rede laboratorial do SUS (doc 9).

O risco biológico também é contemplado na Resolução de Diretoria Colegiada (RDC) no 306 (doc 10), que dispõe sobre o regulamento técnico para o gerenciamento de resíduos de serviços de saúde. Essa 
abordagem foi pioneira no cenário mundial e de extrema importância, considerando os elevados índices de acidentes de trabalho com exposição a material biológico envolvendo resíduos dos serviços de saúde. Apesar de altas taxas, essa RDC contempla apenas orientações para os trabalhadores da área da saúde.

Ainda deve ser salientada a recomendação de autoridades internacionais quanto à adoção de rígidas estruturas nos serviços de saúde, para proteção dos TAS, com elaboração de medidas de segurança ao manejo dos resíduos gerados nos serviços de saúde, para assegurar a proteção adequada, por meio de vacinações, orientações e fornecimento de EPI apropriados ${ }^{(18)}$.

A magnitude dos acidentes com material biológico (ACM), foi melhor explicitada pela Portaria № 777 de 28 de abril de $2004^{(19)}$ que definiu uma lista nacional de notificação compulsória, incluindo o acidente de trabalho com exposição a material biológico. Essa Portaria foi uma das mais importantes normativas relacionadas ao cuidado à saúde dos trabalhadores da área da saúde. Considera a exposição a material biológico como um acidente de trabalho, dada à possibilidade de contaminação e soroconversão já documentadas na literatura (doc 1). Dez anos após sua publicação, a Portaria no 1.271 (doc 11) a modificou e determinou que a notificação deveria ocorrer semanalmente. No entanto, ainda persiste o desafio da subnotificação(4-5).

Os manuais do Ministério da Saúde contribuíram com orientações importantes para os TAS quanto ao embasamento científico referente às condutas que devem ser adotadas, frente ao acidente com material biológico, inclusive no que se refere a importância das notificações. Trabalhadores de outros países encontram informações, por exemplo, em diversos guidelines referentes a temática publicados pelo $\mathrm{CDC}^{(7)}$.

Outra publicação do Ministério da Saúde foi a Política Nacional de Saúde do Trabalhador e da Trabalhadora (doc 12), que, dentre outros aspectos, regulamenta a garantia dos direitos à qualidade no ambiente profissional de todos os trabalhadores, independentemente do local (urbano ou rural), de sua forma de inserção no mercado de trabalho (formal ou informal) ou do vínculo empregatício (doc 12).

A saúde dos trabalhadores da área da saúde é objeto de regulação pela Anvisa, que direciona as suas ações para a redução dos acidentes de trabalho com exposição a material biológico. Todas as resoluções publicadas apresentam as recomendações com os detalhamentos necessários, sendo a especificidade de cada uma demarcada pelos ambientes abordados.

A RDC no 02, de 25 de janeiro de 2010, dispõe sobre o gerenciamento de tecnologias em estabelecimentos de saúde e determina que o seu uso na prestação de serviços de saúde deve ser assegurado em todo o processo de segurança e qualidade (doc 13). O que pode ser considerado um avanço para a saúde e a segurança dos trabalhadores. Essa tecnologia pode ser aliada de unidades críticas para o cuidado, em serviços de saúde, como a Unidade de Terapia Intensiva. Devido às suas peculiaridades, a Anvisa publicou a RDC no 7, de 24 de fevereiro de 2010, que inclui questões para a proteção da saúde do trabalhador (doc 14).

A RDC № 15, de 15 de março de 2012, apresenta os requisitos de boas práticas para o processamento de produtos para saúde, realizados em Centros de Material e Esterilização. Essa norma apresenta uma seção exclusiva para a segurança e saúde no trabalho, abordando, dentre outros itens, os equipamentos de 
proteção individuais recomendados para os trabalhadores da área da saúde, bem como os cuidados com esses equipamentos (doc 15).

A RDC no 11, de 13 de março de 2014, que dispõe sobre os requisitos de boas práticas de funcionamento para os serviços de diálise apresentou uma importante questão para a saúde dos trabalhadores da área da saúde, pouco discutida no cenário nacional. Essa resolução determina que seja vedado ao trabalhador, sem resposta vacinal para hepatite $B$, atuar na sessão de hemodiálise garantindo maior segurança aos trabalhadores da área da saúde (doc 16).

As normativas sobre acidente de trabalho com exposição a material biológico permitem a observação que, gradativamente, as responsabilidades do empregador, dos órgãos competentes em todos os níveis, assim como do empregado foram normalizadas. Essa responsabilidade é coletiva, visto que a divulgação das novas legislações deve ser exaustiva, assim como, o interesse pelo TAS em conhecer a legislação trabalhista e as recomendações para proteção da sua saúde. Conhecer as normas vigentes e identificar seus direitos e deveres é o primeiro passo para se integrar, efetivamente, no campo da saúde do trabalhador ${ }^{(13)}$.

A Coordenação Geral do Programa Nacional de Imunizações, por meio da Nota Informativa no 149/2015 ampliou a oferta da vacina contra hepatite B para a população, independentemente da idade e das condições de vulnerabilidade ${ }^{(20)}$. Isso representou um avanço no programa de atenção à saúde dos brasileiros, em especial dos trabalhadores da área da saúde que ao ingressarem no mercado de trabalho têm maiores possibilidades de apresentarem imunidade contra a doença. Essa medida de grande abrangência além de proteger os trabalhadores resulta em qualidade no trabalho e em economia aos cofres públicos.

Ainda referente à vacinação seria interessante que o Ministério da Saúde aperfeiçoasse mecanismos eficazes para o monitoramento da vacinação dos trabalhadores da saúde antes da admissão, pois são frequentes os estudos que apontam a não vacinação ou vacinação incompleta no momento do acidente ${ }^{(21)}$.

Por outro lado, sabe-se que um indivíduo não respondedor a um primeiro esquema vacinal (três doses), poderá responder a um segundo esquema e aqueles não respondedores há recomendações de que sejam direcionados para áreas de menor exposição a material biológico, ou então, que em caso de acidente envolvendo material biológico, a imunoglobulina para hepatite B seja instituída ${ }^{(22)}$.

Um avanço importante foi a recomendação para a realização do teste de confirmação da imunidade pós-vacinação para hepatite B (Anti-HBs) entre trabalhadores de serviços de diálise (RDC 11/14). A realização desse teste, historicamente, foi apresentado como um aspecto apenas recomendado ${ }^{(23)}$, o que de certa forma não conferia obrigatoriedade do seu fornecimento pelo Sistema Único de Saúde. Entretanto, compreende-se que essa medida deverá ser estendida para todos os TAS, considerando a possibilidade de revacinação e ainda a necessidade de alocação em áreas de menor risco de exposição a material biológico.

Onde há possibilidade de exposição a material biológico, o empregador deve fornecer orientações escritas referentes às rotinas de trabalho, medidas de prevenção de acidente e doenças relacionadas ao trabalho. O TAS deve comunicar imediatamente o acidente ou um incidente ao supervisor do local de trabalho, e quando houver, ao SESMT e à Comissão Interna de Prevenção de Acidente ${ }^{(24)}$. 
Mesmo com a obrigatoriedade da notificação de acidentes envolvendo material biológico, desde a Portaria MS no 777/2004, os índices de subnotificação ainda são altos e constituem um grande desafio para se conhecer a real incidência dos acidentes de trabalho. Estudos demonstram que esses índices dependem do tipo de exposição, da categoria profissional e das políticas de notificação das instituições de saúde ${ }^{(25)}$.

\section{CONCLUSÃO}

A investigação permitiu identificar e analisar 37 recomendações e legislações brasileiras que promovem e protegem a saúde do trabalhador da área da saúde. Da maioria divulgada no ano de 1978, algumas já foram revogadas e muitas atualizadas ou reformuladas, com base em evidências científicas e recomendações internacionais, demonstrando empenho e comprometimento dos órgãos competentes com a saúde do trabalhador.

O Ministério da Saúde e Ministério do Trabalho e Previdência Social publicaram diversas recomendações e normalizações que podem ser utilizadas com a finalidade de diminuir ou eliminar o risco biológico ocupacional. Esses documentos se complementam e as funções dos Ministérios se convergem para tornar a saúde do trabalhador da área da saúde mais protegida.

As legislações abrangem as diversas áreas dos serviços de saúde, como Centro de Material e Esterilização, Hemodiálise, Setor de Processamento de Roupas, Unidade de Terapia Intensiva, Atenção Obstétrica, Banco de Leite, Laboratórios, dentre outras áreas afins. São Documentos que, em seu escopo, possuem determinações específicas para a biossegurança.

A evolução das legislações e recomendações mostra contribuições importantes para a proteção da saúde do trabalhador e, tem agregado novas determinações advindas dos avanços científicos e tecnológicos, subsidiados pelas informações epidemiológicas.

As legislações apresentam desde a normalização para a estrutura dos serviços para a saúde do trabalhador, até o detalhamento específico de medidas protetoras. Destaca-se que as medidas voltadas para a saúde do trabalhador estão contempladas mesmo em legislações cujo escopo está direcionado para a atenção e qualidade à saúde do usuário.

Apesar da abrangência das legislações a sua aplicabilidade fica restrita ao compromisso do empregador para o cumprimento das exigências legais e ao desconhecimento dos trabalhadores sobre seus direitos e deveres, bem como, a baixa adesão às medidas de segurança no trabalho. Essa análise permitiu concluir que no cenário da atenção à saúde do trabalhador existem desafios a serem superados no campo da prática.

A síntese apresentada poderá fundamentar discussões acerca da saúde do trabalhador, tanto para avanços na legislação vigente mediante a identificação de possibilidades de aperfeiçoamentos, quanto para contribuir com estudantes e profissionais da saúde na compreensão deste importante tema no campo da pesquisa, do ensino e da assistência. 


\section{REFERÊNCIAS}

1. Constituição da República Federativa do Brasil de 1988 (BR). Diário Oficial da União [Internet]. Seção 1, página 1, 05 out 1988 [acesso em: 06 abr. 2017]. Disponível em:

http://www.planalto.gov.br/ccivil 03/constituicao/constituicao.htm.

2. Dias MA C, Machado AA, Santos BMO. Acidentes ocupacionais com exposição a material biológico: retrato de uma realidade. Medicina (Ribeirão Preto, Online.) [Internet]. 2012 [acesso em: 06 abr. 2017];45(1):12-22. Disponível em: http://dx.doi.org/10.11606/issn.2176-7262.v45i1p12-22.

3. Yenesew MA1, Fekadu GA1. Occupational exposure to blood and body fluids among health care professionals in bahir dar town, northwest ethiopia. Saf Health Work [Internet]. 2014 [acesso em: 06 abr. 2017];5(1):17-22. Disponível em: http://dx.doi.org/10.1016/j.shaw.2013.11.003.

4. Oliveira AC, Paiva MHRS. Condutas pós-acidente ocupacional por exposição a material biológico entre profissionais de serviços de urgência. Rev Enferm UERJ [Internet]. 2014 [acesso em: 06 abr. 2017];22(1):116-22. Disponível em: http://www.facenf.uerj.br/v22n1/v22n1a18.pdf.

5. Tipple AFV, Silva EAC, Teles SA, Mendonça KM, Souza ACS, Melo DS. Acidente com material biológico no atendimento pré-hospitalar móvel: realidade para trabalhadores da saúde e não saúde. Rev Bras Enferm [Internet]. 2013 [acesso em: 06 abr. 2017];66(3):378-84. Disponível em: http://dx.doi.org/10.1590/s0034-71672013000300012. 6. Riscobiologico.org. Relatório PSBio - Sistema de Vigilância de Acidentes de Trabalho com material biológico em serviços de saúde brasileiros. 1a fase 2002 a 2004. 2a fase 2005 a 2014 [Internet]. Rio de Janeiro: Riscobiologico.org; 2014 [acesso em: 06 abr. 2017]. Disponível em: http://www.riscobiologico.org/psbio/psbio 201411.pdf.

7. Centers for Disease Control and Prevention. Workbook for designing, implementing, and evaluating a sharps injury prevention program [Internet]. Atlanta: Centers for Disease Control and Prevention; 2008 [acesso em: 06 abr. 2017]. Disponível em: http://www.cdc.gov/sharpssafety/pdf/sharpsworkbook_2008.pdf.

8. Congress US. Public Law 106-430. Retrieved July [Internet]. 2000 [acesso em: 06 abr. 2017];31:2004. Disponível em: https://history.nih.gov/research/downloads/PL106-430.pdf.

9. Jagger J. Caring for Healthcare Workers A Global Perspective. Infect Control Hosp Epidemiol [Internet]. 2007 [acesso em: 06 abr. 2017];28(1):1-4. Disponível em: http://dx.doi.org/10.1086/511655.

10. Lamontagne F, Abiteboul D, Lolom I, Pellissier G, Tarantola A, Descamps JM, Bouvet E. Role of safety-engineered devices in preventing needlestick injuries in 32 French hospitals. Infect Control Hosp Epidemiol [Internet]. 2007 [acesso em: 06 abr. 2017];28(1):18-23. Disponível em: https://doi.org/10.1086/510814.

11. Ministério do Trabalho (BR) Normas Regulamentadoras [Internet]. Brasília: Ministério do Trabalho; 14 set. 2015 [acesso em: 06 abr. 2017]. Disponível em: http://trabalho.gov.br/seguranca-e-saude-no-

trabalho/normatizacao/normas-regulamentadoras.

12. Agência Nacional de Vigilância Sanitária (BR). Institucional [Internet]. Brasília: Agência Nacional de Vigilância Sanitária; 2016 [acesso em: 06 abr. 2017]. Disponível em: http://portal.anvisa.gov.br/institucional.

13. Galon T, Marziale MHP, Souza WL. A legislação brasileira e as recomendações internacionais sobre a exposição ocupacional aos agentes biológicos. Rev Bras Enferm [Internet]. 2011 [acesso em: 06 abr. 2017];64(1):160-7.

Disponível em: http://dx.doi.org/10.1590/s0034-71672011000100023.

14. Occupational Safety \& Health Administration - OSHA [internet]. Washington, DC: United States, Department of Labor; 2016 [acesso em: 30 jul. 2016]. Disponível em: http://www.ecfr.gov/cgi-bin/textidx?SID=34fba2ee7d5e64d1ab644e79ae1db4bc\&mc=true\&node=pt29.5.1910\&rgn=div5\#se29.5.1910 1133.

15. Occupational Safety \& Health Administration - OSHA [internet]. Washington, DC: United States, Department of Labor; 2016 [acesso em: 30 jul. 2016]. Disponível em:

https://www.osha.gov/pls/oshaweb/owadisp.show_document?p_table=DIRECTIVES\&p_id=4632.

16. Marziale MHP, Santos HEC, Cenzi CM, Rocha FLR, Trovó MEM. Consequences of occupational exposure to biological material among workers from a university hospital. Esc Anna Nery [Internet]. 2014 [acesso em: 06 abr. 2017];18(1):11-6. Disponível em: http://dx.doi.org/10.5935/1414-8145.20140002.

17. Rapparini C, Reinhart EL. Manual de implementação: programa de prevenção de acidentes com materiais perfurocortantes em serviços de saúde [Internet]. São Paulo: Fundacentro; 2010 [acesso em: 06 abr. 2017]. Disponível em: http://www.riscobiologico.org/upload/arquivos/workbook_final_20100308.pdf.

18. Walkinshaw E. Medical waste-management practices vary across Canada. CMAJ [Internet]. 2011 [acesso em: 06 abr. 2017];183(18):E1307-8. Disponível em: http://dx.doi.org/10.1503/cmaj.109-4032. 
19. Portaria no 777, de 28 de abril de 2004 (BR). Dispõe sobre os procedimentos técnicos para a notificação compulsória de agravos à saúde do trabalhador em rede de serviços sentinela específica, no Sistema Único de Saúde SUS. Diário Oficial da União [Internet]. 29 abr. 2004 [acesso em: 06 abr. 2017], Seção 1, p. 37. Disponível em: http://bvsms.saude.gov.br/bvs/saudelegis/gm/2004/prt0777_28_04_2004.html.

20. Ministério da Saúde. Nota informativa no 149, de 2015 CGPNI/DVIT/SVS/MS. Informa as mudanças no Calendário Nacional de Vacinação para o ano de 2016. Brasília: Ministério da Saúde; 2015 [acesso em: 06 abr. 2017]. Disponível em: http://www.aids.gov.br/sites/default/files/anexos/legislacao/2015/58563/nota_informativa_149_pdf_23535.pdf. 21. Jardim EMA, Carvalho PAM, Silva RP, Souza AC. Vacinação contra Hepatite B e resposta vacinal em trabalhadores da área da saúde envolvidos em acidentes com material biológico. Acta Ciências e Saúde [Internet]. 2014 [acesso em: 06 abr. 2017];2(2):14-24. Disponível em: http://www2.Is.edu.br/actacs/index.php/ACTA/article/view/58.

22. Ministério da Saúde. Manual de Normas de Vacinação [Internet]. Brasília: Ministério da Saúde; 2001 [acesso em: 06 abr. 2017]. Disponível em: http://bvsms.saude.gov.br/bvs/publicacoes/funasa/manu_normas_vac.pdf.

23. Ministério da Saúde. Exposição a materiais biológicos. xx. Saúde do trabalhador. Protocolos de complexidades variadas [Internet]. Brasília: Editora do Ministério da Saúde; 2011 [acesso em: 06 abr. 2017]. Disponível em: http://bvsms.saude.gov.br/bvs/publicacoes/protocolo_expos mat_biologicos.pdf.

24. Portaria no 485, de 11 de novembro de 2005 (BR). Aprova a Norma Regulamentadora no 32 (Segurança e Saúde no Trabalho em Estabelecimentos de Saúde). Diário Oficial da União [Internet]. 16 nov 2005 [acesso em: 06 abr. 2017], Seção 1, p. 80-94. Disponível em:

http://pesquisa.in.gov.br/imprensa/jsp/visualiza/index.jsp?jornal=1\&pagina=80\&data=16/11/2005.

25. Luize PB, Canini SRMS. Gir E, Toffano SEM. Procedures after exposure to biological material in a specialized cancer hospital. Texto contexto - enferm. [Internet]. 2015 [acesso em: 06 abr. 2017];24(1):170-7. Disponível em:

http://dx.doi.org/10.1590/0104-07072015002700013. 